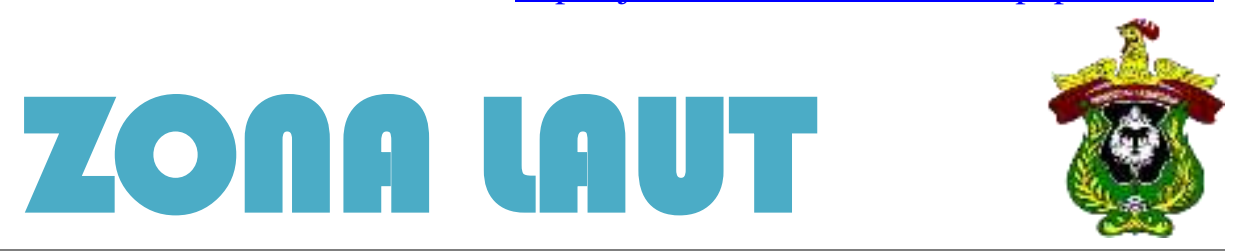

JURNAL INOVASI SAINS DAN TEKNOLOGI KELAUTAN

\title{
DESAIN PELABUHAN WISATA UNTUK MENUNJANG PARIWISATA DANAU TOBA
}

\author{
*Amelia Azwar, Arif Fadillah dan Shanty Manullang \\ Teknik Perkapalan, Fakultas Teknologi Kelautan, Universitas Darma Persada \\ *amelia_azwar@gmail.com
}

\begin{abstract}
Abstrak
Tempat pariwisata di Indonesia telah menjadi destinasi yang banyak dikunjungi bagi wisatawan dalam negeri maupun luar negeri. Danau Toba merupakan destinasi wisata prioritas, sehingga pariwisata ini sangat berpotensi untuk dikembangkan sebagai salah satu aset yang digunakan sebagai sumber yang menghasilkan bagi bangsa dan negara. Penelitian ini dilakukan untuk merencanakan desain pelabuhan wisata dan tata kelola pelabuhan di kawasan Danau Toba dengan tersedianya transportasi kapal ferry, kapal wisata, bus air. Perencanaan pelabuhan yang diteliti menggunakan standar fasilitas yang sangat mendukung mengacu pada Petunjuk Teknis Rencana Induk pelabuhan, dan PERMENPAR nomor 3 Tahun 2018 dengan menambahkan beberapa fasilitas untuk seaplane bases dan WIG (Wing in Ground Effect) seperti landasan pesawat amphibi yang mengacu pada U.S Departement Of Transportation, Federal viation Administration dalam dokumen Advisory Circular (AC) No.150/5395-1B. Untuk kelengkapan fasilitas di pelabuhan dan seaplane bases digunakan metode Benchmarking dengan mengacu pada pelabuhan ferry dan seaplane bases yaitu dermaga eksekutif Pelabuhan Merak, Singapore cruise center, Harbour Bay Batam, Jantzen Beach Seaplane Bases, Traves Seaplane Bases, Lake Hood Seaplane Bases. Pelabuhan ini direncanakan melalui beberapa tahap pembangunan menggunakan data pengunjung wisatawan dengan proyeksi kunjungan 20 tahun kedepannya. Berdasarkan hasil proyeksi maka jumlah penumpang terbanyak terjadi pada tahun 2040 dengan jumlah 264.202 orang.
\end{abstract}

Kata Kunci: Danau Toba, Fasilitas Pelabuhan, Seaplane Bases, Bus Air.

\begin{abstract}
Tourist attractions in Indonesia have become a popular destination for domestic and foreign tourists. Lake Toba is a priority tourist destination, so this tourism has the potential to be developed as an asset that is used as a source of income for the nation and state. This research was conducted to plan the design of a tourist port and port management in the Lake Toba area with the availability of transportation ferries, tourist boats, water buses. The researched port planning uses very supportive facility standards referring to the port Master Plan Technical Guidelines, and PERMENPAR number 3 of 2018 by adding several facilities for the seaplane. bases and WIG (Wing in Ground Effect) are like runways amphibious that refer to U.S Department Of Transportation, Federal Aviation Administration in the document Advisory Circular (AC) No. 150 / 5395-1B. For complete facilities at the port and seaplane bases, the method is used benchmarking by referring to the port ferry and seaplane. bases are the executive Merak Harbor, Singapore cruise center, Harbor Bay Batam, Jantzen Beach Seaplane Bases, Traves Seaplane Bases, Lake Hood Seaplane Bases. This port is planned to go through several stages of development using tourist visitor data with projected visits in the next 20 years. Based on the projection results, the highest number of passengers will occur in 2040 with 264,202 people.
\end{abstract}

Keywords: Lake Toba, Port Facilities, Seaplane Bases, Water Bus.

\section{PENDAHULAN}

Indonesia merupakan negara kepulauan terbesar di dunia yang memiliki posisi geografis yang sangat strategis dan mempunyai kaya akan keindahan alam, yang di tinjau dari aspek ekonomi dan lingkungan, sosial-budaya, hukum dan keamanan. Maka dari itu pariwisata merupakan sektor yang ikut berperan penting copyright is published under Lisensi Creative Commons Atribusi 4.0 Internasional. 
dalam usaha peningkatan pendapatan, karena pariwisata sangat berpotensi untuk dikembangkan sebagai salah satu aset yang di gunakan sebagai sumber yang menghasilkan bagi bangsa dan negara. Dari destinasi wisata prioritas dan destinasi wisata super prioritas Danau Toba merupakan destinasi yang pertama.

Pariwisata di Indonesia adalah destinasi yang banyak dikunjungi bagi wisatawan dalam negeri maupun luar negeri. Di Indonesia memiliki sepuluh destinasi wisata prioritas yaitu Danau Toba, Tanjung Kelayang, Tanjung Lesung, Kepulauan Seribu, Borobudur, Bromo Tengger Semeru, Mandalika, Labuan Bajo, Wakatobi, dan Morotai. Dan memiliki 4(empat) destinasi wisata super prioritas yaitu, Danau Toba, Borobudur, Mandalika, Labuan Bajo. Dari destinasi wisata prioritas dan destinasi wisata super prioritas Danau Toba merupakan destinasi yang pertama.

Menurut Badan Pusat Statistik Kabupaten Toba Samosir Tahun 2019[1]. Jumlah wisatawan mancanegara (wisman) yang berkunjung di Sumatera Utara melalui 4 (empat) pintu masuk yaitu Bandar Udara Kualanamu, Pelabuhan Laut Belawan, Pelabuhan Laut Tanjungbalai Asahan, dan Bandar Udara Silangit pada bulan Oktober 2019 mencapai 22.556 kunjungan, mengalami kenaikan 14,40 persen dibanding yang datang pada bulan September 2019 mencapai 19.717 kunjungan.

Danau Toba adalah danau kaldera terbesar di dunia yang terletak di Provinsi Sumatera Utara, secara geografis terdapat antara ordinat 2010' LU - 300' LU dan 98050' BT - 99050' BT, memiliki luas 90 x 30 km2 dan juga merupakan sebuah kaldera volcano-tektonik (kawah gunung api raksasa) Kuarter terbesar di dunia. Sebagai danau volcano tektonik terbesar di dunia, Danau Toba mempunyai ukuran panjang $87 \mathrm{~km}$ berarah Barat laut-Tenggara dengan lebar 27 km dengan ketinggian 904 meter dpl dan kedalaman danau yang terdalam 505 meter. Kawasan ini merupakan bagian dari wilayah administrasi dari 8 (delapan) kabupaten yaitu Kabupaten Samosir, Kabupaten Toba Samosir, Kabupaten Dairi, Kabupaten Karo, Kabupaten Humbang Hasundutan, Kabupaten Tapanuli Utara dan Kabupaten Simalungun dan Kabupaten Pakpak Bharat.

Tata kelola pelabuhan di kawasan Danau Toba selama ini tidak sesuai ketentuan dan aturan standar Internasional, baik terkait pelayanan, fasilitas, pelayaran maupun kepelabuhanan untuk meningkatkan unsur keselamatan dalam pelayaran karena adanya kejadian tenggelamnya KM Sinar Bangun tahun 2018. Namun tanggung jawab dan tata kelola pelabuhan belum terjadi di Danau Toba yang dikelilingi tujuh kabupaten itu. Sebagai sarana penunjang pariwisata Indonesia peran transportasi sangatlah penting untuk daya tarik wisatawan di wilayah tersebut, untuk itu diperlukan pengembangan transportasi di Danau Toba berupa kapal Wisata, Tradisional, Bus Air, Seaplane Bases dan Wing Ground Effect. Dengan begitu dibutuhkan pelabuhan Wisata untuk menunjang fasilitas berstandar Internasional dengan memadukan kebudayaan Indonesia, dan dilengkapi dengan fasilitas untuk bersandar Seaplane Bases, agar pelabuhan ini dapat dijangkau oleh beberapa jenis transportasi yang memeberikan kemudahan para wisatawan untuk berkunjung ke Danau Toba, dengan mempertimbangkan pelabuhan yang sudah ada di daerah tersebut.

\section{KAJIAN PUSTAKA}

Danau Toba merupakan perairan yang berada di Sumatera Utara yang mempunyai peran sebagai multisektoral seperti pusat kepariwisataan. Danau Toba mempunyai luas perairan sebesar $1.124 \mathrm{~km}^{2}$, dengan volume air 256,2 x $109 \mathrm{~m}^{3}$, dan maksimum kedalaman $508 \mathrm{~m}$ [2]. Danau Toba mempunyai komponen wisata alami danau, wisata geopark atau disebut dengan taman bumi dan wisata budaya daerah (Batak) yang menjadi tujuan wisata. Destinasi pariwisata di Danau Toba mengalami peningkatan dengan begitu Danau Toba menjadi Kawasan Strategis Pariwisata Nasional (KSPN) dengan kabupaten Toba Samosir, Samosir, Simalungun, Tapanuli Utara, Karo, Humbang Hasundutan, dan Dairi [3].

Pariwisata adalah elemen yang didalamnya terdiri dari wisatawan, daerah tujuan wisata, perjalanan industri dan tempat lainnya sebagai kegiatan pariwisata. Pariwisata begitu indah kaya akan wisata budaya dengan banyaknya peninggalan-peninggalan, adat dan budaya serta keanekaragaman seni yang dapat menarik wisatawan lokal maupun wisatawan mancanegara[4]. Dalam Peraturan Pemerintah Republik Indonesia Nomor 61 Tahun 2009 Tentang Kepelabuhanan dijelaskan bahwa Pelabuhan adalah tempat yang terdiri dari daratan dan perairan di sekitarnya dengan batas-batas tertentu sebagai tempat kegiatan pemerintahan dan kegiatan ekonomi yang digunakan sebagai tempat kapal bersandar, berlabuh, naik turun penumpang dan/atau bongkar muat barang yang dilengkapi dengan fasilitas keselamatan pelayaran dan kegiatan penunjang pelabuhan serta sebagai tempat perpindahan intra dan antar moda transportasi[5]. Peraturan Menteri Pariwisata Republik Indonesia Nomor 3 Tahun 2018 Tentang Petunjuk Operasional Pengelolaan Dana Alokasi Khusus Fisik Bidang Pariwisata, untuk meningkatkan kualitas rencana induk pelabuhan agar

copyright is published under Lisensi Creative Commons Atribusi 4.0 Internasional. 
memenuhi standar perencanaan, teknis, dan keselamatan pelayaran[6]. Menurut Peraturan Menteri Perhubungan Nomor 39 Tahun 2015 tentang standar pelayanan penumpang angkutan laut, pasal 3 dijelaskan Standar pelayanan penumpang di Pelabuhan[7]. Perencanaan Pelabuhan dalam merencanakan Seaplane Bases dan Wing Ground Effect untuk beberapa fasilitas yang digunakaN [8] .

Seaplane Bases lebih praktis dan fleksibel karena jika tidak dibutuhkan sewaktu-waktu pelampungnya dapat dilepas, namun kelemahannya adalah endurance dan daya angkut pesawat sangat berkurang saat pelampung dipasang karena menimbulkan daya hambat dan menambah beban. Pesawat ini umumnya hanya digunakan untuk misi-misi yang ringan seperti survey, rekreasi, dan hobby[9]. Kendaraan amphibi Coach atau bus air merupakan hasil dari perkembangan teknologi yang pesat dan inovatif. Transportasi amphibi ini berbentuk bus yang dapat mengangkut 60 orang di laut dan di daratan. Bus ini mempunyai dua sistem penggerak seperti roda untuk di darat dan propeller seperti kapal untuk melaju di perairan [10].

\section{METODE}

Metode penelitian ini dimulai dengan menentukan fasilitas apa saja yang digunakan di pelabuhan, dengan menggunakan berbagai macam metode tergantung dari fasilitas yang dibutuhkan.

\subsection{Metode Benchmarking}

Merupakan metode yang dilakukan dengan suatu proses benchmark yaitu membandingan satu dengan lainnya baik dari segi internal atau eksternal dengan mengumpulkan berbagi informasi dan data yang digunakan sebagai acuan. Pada perencanaan pelabuhan ini dilakukan benchmarking dari beberapa pelabuhan yang sudah ada dengan mempertimbangkan fasilitas yang ada di pelabuhan dan yang akan digunakan untuk wisatawan dan penempatan ruangan yang digunakan.

\subsection{Metode Perencanaan Fasilitas di Pelabuhan}

1. Kedalaman Alur dan Lebar Alur Pelayaran

Digunakan untuk mengarahkan kapal menuju ke arah dermaga, untuk merencanakan alur pelayaran untuk pelabuhan penting untuk memperhitungkan kedalaman alur dan lebar alur pelayaran[11], $\mathrm{D}=$ kedalaman alur(m), $\mathrm{d}=\operatorname{draft}(\mathrm{m}), \mathrm{B}=$ lebar kapal, dengan persamaan sebagai berikut :

$$
\mathrm{D} \geq 1,1 \times \mathrm{d}
$$

$$
\text { Lebar } 1 \text { arah }=4,8 \times \text { B }
$$

2. Metode Perencanaan Kolam Putar

Kapal yang bersandar di dermaga menggunakan perhitungan kolam putar untuk mendapatkan posisi yang tepat jika harus menunggu kapal lain maka dibutuhkan area kolam putar [11]Loa adalah panjang kapal, B merupakan lebar kapal, AT merupakan area tambat dan L adalah panjang kapal. Dengan persamaan sebaga berikut :

$$
\begin{aligned}
& \text { ATR }=\pi \times(1,5 \times \text { Loa })^{2} \\
& \text { AT }=\mathrm{n} x(1,5 \times \text { L }) \times\left(\frac{4}{3} \times B\right)
\end{aligned}
$$

3. Kebutuhan Fasilitas di Pelabuhan

Menurut Petunjuk Teknis Penyusuanan Rencana Induk Pelabuhan [12] ditentukan sebagai berikut ini dengan sesuai kebutuhan yang digunakan :

Tabel 1. Ruang Tunggu Penumpang

\begin{tabular}{lc}
\hline Ruang & Kebutuhan \\
\hline Ruang Tunggu Penumpang & $4 \mathrm{~m}^{2} /$ orang \\
Ruang Penyimpanan & $4 \mathrm{~m}^{2} /$ orang \\
\hline
\end{tabular}




\begin{tabular}{lc}
\hline Ruang & Kebutuhan \\
\hline Barang & \\
Toilet & Min $4.5 \mathrm{~m}^{2}$ \\
\hline
\end{tabular}

Tabel 2. Kebutuhan Fasilitas di Pelabuhan

\begin{tabular}{ll}
\hline Ruang & Kebutuhan \\
\hline Ruang Administrasi & $4 \mathrm{~m}^{2} /$ orang \\
Ruang Kasir & $4 \mathrm{~m}^{2} /$ orang \\
Ruang Kepala Pelabuhan & $10 \mathrm{~m}^{2} /$ orang \\
Ruang Tiket & $4 \mathrm{~m}^{2} /$ orang \\
Pantry & $4.0 \mathrm{~m}^{2}$ \\
Ruang Tunggu & $4 \mathrm{~m}^{2} /$ orang \\
Toilet Staff & $4.0 \mathrm{~m}^{2}$ \\
Toilet Umum & ${\mathrm{Min} 2.0 \mathrm{~m}^{2}}_{\text {TIC (Tourist Information Center })} 80 \mathrm{~m}^{2}$ \\
Lampu Taman & $\mathrm{Jrak} 0,8-1 \mathrm{~m}_{\text {Pusat Kuliner }}^{80 \mathrm{~m}^{2}}$ \\
Tempat Ibadah & $20 \mathrm{~m}^{2} /$ gerai \\
Lebar jalur pejalan kaki & 30 Orang \\
Tempat Parkir & $2 \mathrm{~m}$ \\
\hline
\end{tabular}

\subsection{Metode Perencanaan Fasilitas di Daratan}

1. Fender (Bantalan Sandar)

Fender digunakan untuk memisahkan antara kapal dengan dermaga agar mengurangi risiko rusaknya badan kapal dan bedan dermaga. OCDI (1991) memberikan jarak interval antara fender sebagai fungsi kedalaman air sebagai berikut :

Tabel 3. Jarak Antara Fender

\begin{tabular}{ll}
\hline Kedalaman Air $(\mathrm{m})$ & Jarak Antara Fender $(\mathrm{m})$ \\
\hline $4-6$ & $4-7$ \\
$6-8$ & $7-10$ \\
$8-10$ & $10-15$ \\
\hline
\end{tabular}

2. Panjang Dermaga

Menurut Perencanaan Pelabuhan karya tulis Bambang Triatmodjo, jika dermaga yang digunakan lebih dari satu tambatan kapal, maka diberi jarak 10\% kali panjang kapal yang terbesar yang ada di pelabuhan itu, diantara dua panjang kapal yang sejajar[13]. Dengan persamaan sebagai berikut ini :

$$
\mathrm{L}_{\mathrm{p}}=\mathrm{nL}_{\mathrm{oa}}+(\mathrm{n}+1) \times 10 \% \times \mathrm{L}_{\mathrm{oa}}
$$

3. Kedalaman Kolam Dermaga

Menurut Standar Nasional Indonesia (SNI) kedalaman kolam dermaga ditentukan dengan menambahkan ruang bebas di bawah lunas (under keel clearance) dengan draft maksimum kapal rencana, digunakan persamaan sebagai berikut :

$$
d=\text { draft }_{\max }+\mathrm{UKC}
$$

\subsection{Fasilitas Perairan Untuk Seaplane Base}

Lebar landasan untuk Seaplane adalah lebar yang biasa mengakomodasi Seaplane, namun lebar sebagian besar Seaplane Bases minimum 200 feet. Untuk kedalaman landasan Seaplane harus bersih dari penghalang yang berada di kedalaman 4 feet. Untuk kedalaman dari Landasan ini memiliki minimum 4 feet atau 6 feet lebih baik. 
Taxi Channels adalah fasilitas utama atau fasilitas minimum yang harus tersedia di Seaplane Bases, Taxi Channels adalah jalur yang menghubungkan antara landasan air dengan fasilitas di darat,, area jangkar, ketentuan ukuran untuk Taxi Channels. Minimum lebar adalah 125 feet (direkomendasikan 150 feet), Minimum kedalaman 4 feet, Untuk Taxi channels yang dirancang dengan menggunakan 2 arah maka jarak anta sayap Seaplane adalah 50 feet. Turning Basin merupakan kolam putar atau tempat memutarnya Seaplane untuk memasuki atau keluar dari pelabuhan. Minimum untuk diameter dari kolam putar ini adalah 200 feet atau $60 \mathrm{~m}$. Anchorage Areas adalah area yang digunakan untuk seaplane bersandar di tengah laut dengan menggunakan mooring buoys dengan di ikatkan pada jangkar yang telah ditanam di bawah laut, luas dari area jangkar ini tergantung dari dimensi Seaplane yang akan ditentukan. Jarak di setiap area seaplane tidak boleh kurang dari 125 feet atau sekitar $38 \mathrm{~m}$.

\section{HASIL DAN PEMBAHASAN}

Berdasarkan data yang didapat menggunakan analisa proyeksi jumlah pengunjung untuk 20 tahun kedepannya pada Grafik 1. sebagai berikut :

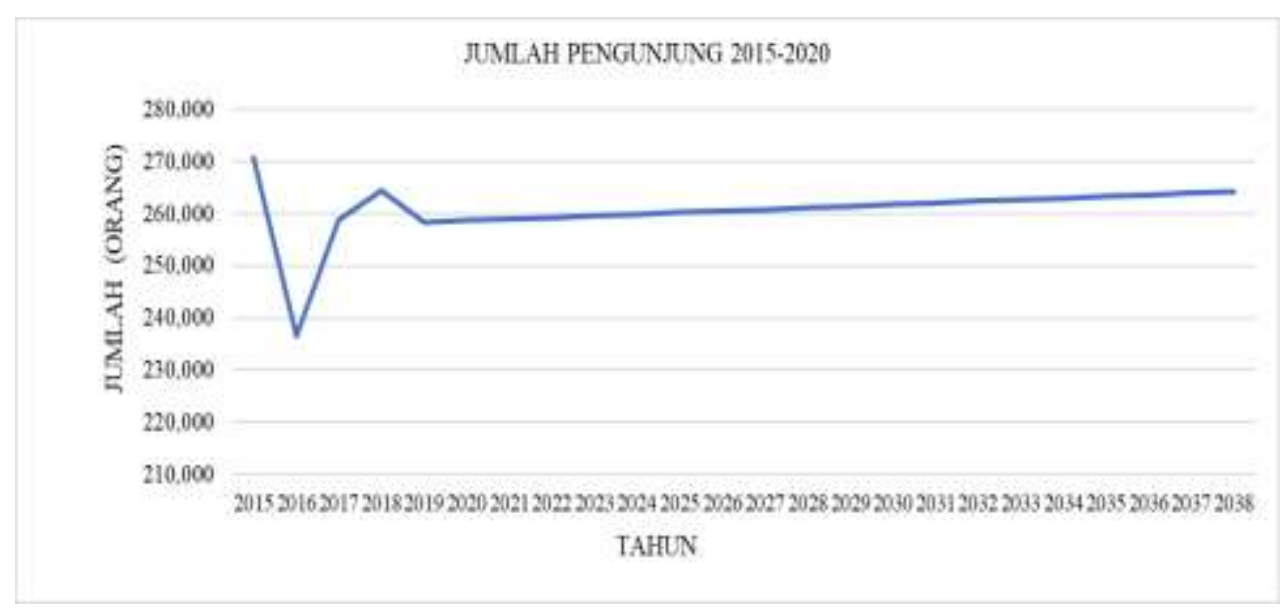

Gambar 1. Jumlah Pengunjung

Pada gambar 1. proyeksi data yang ada menunjukkan hasil analisa untuk 20 tahun ke depan jumlah pengunjung mengalami penurunan dari tahun 2020 karena adanya pandemi COVID-19 yang merupakan penyebaran coronavirus disease 2019, singkatan dari COVID-19 di seluruh dunia. Sehingga kasus tersebut semakin hari semakin naik mengakibatkan pembatasan perjalanan, karantina, pemberlakuan, jam malam, penundaan dan pembatalan acara, serta penutupan fasilitas, berbagai penutupan perbatasan negara atau pembatasan penumpang yang masuk, penapisan di bandara dan stasiun kereta, serta informasi perjalanan mengenai daerah dengan transmisi lokal. Sekolah dan universitas telah ditutup baik secara nasional atau lokal, dan mengalami kenaikan pada tahun 2021 hingga 2040.

Tabel 4. Data Transportasi Pelabuhan Wisata

\begin{tabular}{llllllll}
\hline \multirow{2}{*}{ No. } & $\begin{array}{l}\text { Transportasi } \\
\text { Pelabuhan Wisata }\end{array}$ & Panjang $(\mathrm{m})$ & Lebar $(\mathrm{m})$ & Tinggi $(\mathrm{m})$ & Draft $(\mathrm{m})$ & $\begin{array}{l}\text { capacity } \\
\text { (Orang) }\end{array}$ & $\begin{array}{l}\text { Kendaraan } \\
\text { (Unit) }\end{array}$ \\
\hline 1 & Seaplane Bases & 12,75 & 17,68 & 3,84 & - & 11 & - \\
2 & Amphibi Coach & 13,5 & 2,5 & 3,8 & 1 & 16 & - \\
3 & Kapal Ferry & $10,00-48,50$ & $8,00-13,0$ & $1,80-3,00$ & $0,94-2,00$ & $40-280$ & $8-32$ \\
4 & Kapal Wisata & 21,5 & 7,5 & 90 & - & 60 & - \\
5 & Kapal Tradisional & 19,77 & 4,4 & 9 & - & 60 & - \\
6 & Wing Ground Effect & 17,2 & 5 & 3,5 & - & 8 & - \\
\hline
\end{tabular}




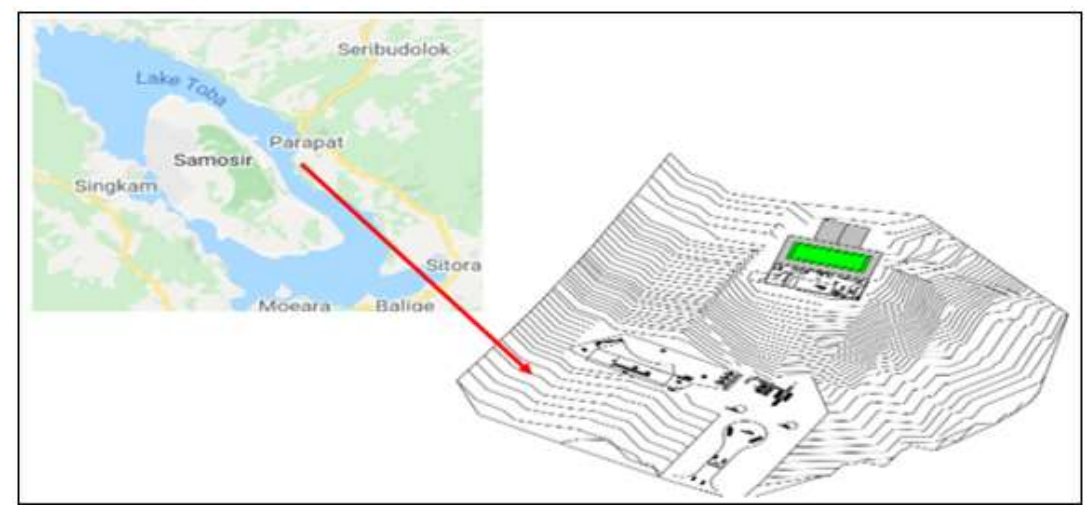

Gambar 2. Layout Desain Pelabuhan Wisata

Pada Gambar 2. merupakan layout desain pelabuhan dengan lokasi perencanaan pelabuhan wisata berada di Kabupaten Simalungun, Kota Parapat, dengan letak geografis $2^{\circ} 38^{\prime} 50.03^{\prime \prime} U$ dan $98^{\circ} 55^{\prime} 34.34^{\prime \prime} \mathrm{T}$ dengan beberapa fasilitas yang digunakan pada pelabuhan wisata seperti alur pelayaran dengan ukuran lebar $59 \mathrm{~m}$, kolam putar dengan ukuran $17.000 \mathrm{~m}^{2}$, terdapat dua area tambat dengan masing-masing ukuran $1300 \mathrm{~m}^{2}$, dan beberapa fasilitas untuk pelabuhan dan Seaplane bases dan Wing Ground Effect.

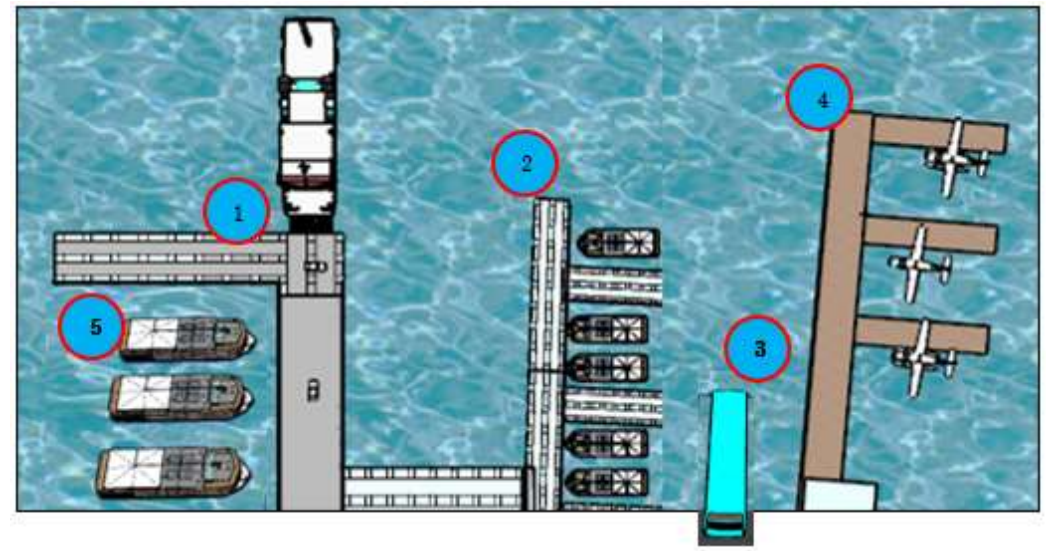

Gambar 3. Visualisasi Pelabuhan Wisata

Pada Gambar 3. merupakan visualisasi dermaga yang terdapat pada pelabuhan wisata, nomor 1 merupakan perencanaan kapal ferry, nomor 2 perencanaan kapal wisata, nomor 3 bus air, nomor 4 untuk perencanaan Seaplane Bases dan Wing Ground Effect dan nomor 5 untuk kapal tradisional.

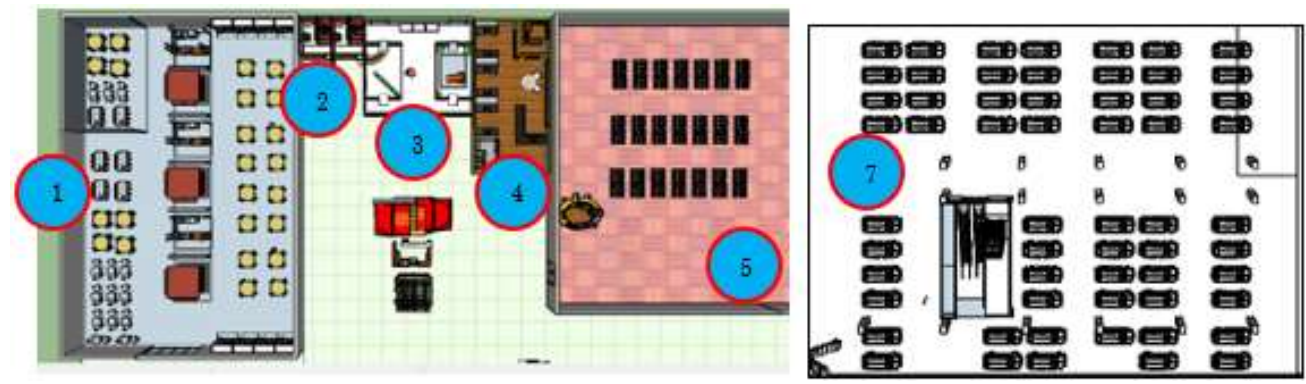

Gambar 4. Fasilitas dipelabuhan wisata

Pada Gambar 4. terdapat beberapa fasilitas yang ada dipelabuhan dengan keterangan gambara pada nomor :

1. Food court

2. Ruang Ibu Menyusui

3. Area Bermain Anak
4. Kantor Pelabuhan

5. Ruang Tunggu

6. Area Parkir 


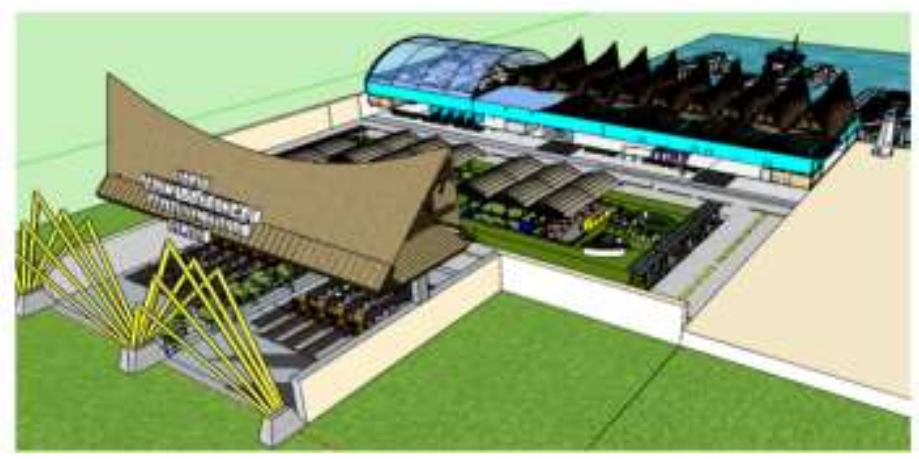

Gambar 4. Desain Pelabuhan Wisata

Desain Pelabuhan Wisata dengan luas $4350 \mathrm{~m}^{2}$ dengan spesifikasi perencanaan ruang tunggu luas $1950 \mathrm{~m}^{2}$, dapat menampung 504 orang kursi biasa dan 30 sofa untuk disabelitas, dan terdapat toilet untuk umum dan disabelitas, 2 minibar, 1 pintu masuk dan 2 pintu keluar. Luas Kantor Pelabuhan $136 \mathrm{~m}^{2}$. Pusat Informasi Wisata / TIC (Tourist Information Center) dengan luas dari $80 \mathrm{~m}^{2}$. Toilet direncanakan untuk perencanaan yaitu seluas $130 \mathrm{~m}^{2}$. Terdapat 3 toilet di masing-masing ruang tunggu, 3 toilet di luar ruang tunggu, dan toilet untuk disabelitas. Food Court atau Pusat Kuliner setiap gerai memiliki luas 4 x $5 \mathrm{~m}$ pada perencanaan ini memiliki 6 gerai, dengan 8 wastafel, dapat menampung 160 orang. Tempat Ibadah mempunyai luas 15,5 x 9 $\mathrm{m}$ dengan 2 tempat wudhu. Perencanaan Jalur Pejalan Kaki memiliki lebar $3 \mathrm{~m}$ dan 4 meter pada Jalur Pejalan Kaki untuk Taman. Perencanaan Tempat Parkir menggunakan jenis pola parkir dengan menggunakan sudut $90^{\circ}$, kapasitas penampungan adalah 59 mobil. Dermaga yang digunakan untuk Seaplane Bases dan WIG adalah dermaga jenis Pier dengan panjang dermaga mengikuti sesuai dengan panjang Seaplane dengan panjang $15 \mathrm{~m}$, dengan kapasitas 3 Seaplane, dengan ukuran panjang landasan air $300 \mathrm{~m}$, lebar 62 m, Kedalaman 0-18m. Lebar dari Taxi Channel yaitu sebesar 40 m. Diameter dari Turning Basin yang ditentukan untuk perencanaan pelabuhan ini adalah $100 \mathrm{~m}$.

Tahapan untuk pengembangan pelabuhan wisata untuk 20 tahun kedepannya dengan 3 tahapan seperti Tabel 5. berikut ini :

Tabel 5. Tahapan Pembangunan Pelabuhan Wisata

\begin{tabular}{llllll}
\hline \multirow{2}{*}{ No } & Fasilitas & \multirow{2}{*}{$\begin{array}{l}\text { Satuan } \\
\text { Tahap I }\end{array}$} & $\begin{array}{l}\text { Pengembangan } \\
\text { Tahap II }\end{array}$ & $\begin{array}{l}\text { Pengembangan } \\
\text { Tahap III }\end{array}$ \\
\hline 1 & Total Panjang Dermaga & $\mathrm{m}$ & 102 & 150 & 210 \\
2 & Panjang Dermaga untuk Kapal & $\mathrm{m}$ & 43 & 43 & 43 \\
3 & Jumlah Fender & $\mathrm{Unit}$ & 59 & 59 & 59 \\
4 & Panjang Dermaga Untuk Seaplane & $\mathrm{m}$ & 15 & 15 & 15 \\
5 & Terminal Penumpang & $\mathrm{m}^{2}$ & 9075 & 9075 & 9075 \\
6 & Ruang Tunggu I & $\mathrm{m}^{2}$ & 1950 & 1950 & 1950 \\
7 & Ruang Tunggu II & $\mathrm{m}^{2}$ & 360 & 360 & 360 \\
8 & Ruang Tunggu III & $\mathrm{m}^{2}$ & 360 & 360 & 360 \\
9 & Area Tempat Parkir Seaplane & $\mathrm{m}$ & 9000 & 9000 & 9000 \\
10 & Hanggar & $\mathrm{m}$ & $22,5 \times 30$ & $22,5 \times 31$ & $22,5 \times 32$ \\
11 & Tempat Parkir Umum & $\mathrm{m}$ & $52,5 \times 55$ & $52,5 \times 56$ & $52,5 \times 57$ \\
12 & Tempat Parkir Bus & $\mathrm{m}$ & $18 \times 14$ & $19 \times 14$ & $20 \times 14$ \\
13 & Jumlah Lampu Jalan & $\mathrm{Unit}$ & 20 & 20 & 20 \\
14 & Panjang Jalan & $\mathrm{m}$ & 70 & 70 & 70 \\
15 & Mercusuar & $\mathrm{m}$ & 10 & 10 & 10 \\
16 & Kantor Pelabuhan & $\mathrm{m}$ & 136 & 136 & 136 \\
17 & Hotel & $\mathrm{m}$ & - & 9075 & 9075 \\
18 & Ball Room & $\mathrm{m}$ & - & - & $42 \times 24$ \\
19 & Taman dan Sport Center & $\mathrm{m}$ & - & - & $75 \times 25$ \\
20 & Jumlah Tempat duduk & $\mathrm{Unit}$ & - & - & 30 \\
21 & Kolam Renang & $\mathrm{m}$ & - & - & $25 \times 25$ \\
22 & Pemadam Kebakaran & $\mathrm{m}$ & - & $17 \times 13$ & $25 \times 23$ \\
23 & Police Station & $\mathrm{m}$ & - & 1 & $18 \times 13$ \\
24 & Jumlah Mobil Polisi & $\mathrm{Unit}$ & - & & 1 \\
25 & Jumlah Mobil Ambulance & $\mathrm{Unit}$ & - & & \\
\hline
\end{tabular}




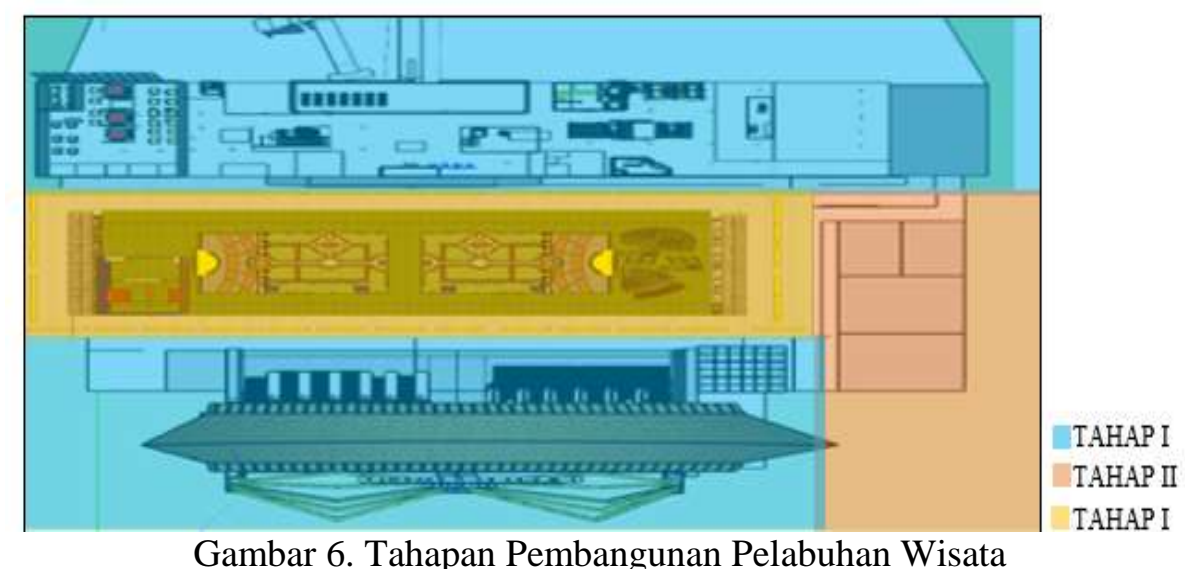

Pada Gambar 6 Perencanaan pelabuhan wisata ini mempunyai 3 tahapan dalam pembangunannya terdapat pada gambar 2. yaitu tahap I tahun 2020 tahap II tahun 2025 dan tahap III tahun 2040, dengan penambahan fasilitas pada setiap tahapan.

\section{KESIMPULAN}

Desain pelabuhan yang dirancang untuk kapal wisata sesuai dengan standar dari Petunjuk Teknis Rencana Induk Pelabuhan, Peraturan Menteri Pariwisata Nomor 3 Tahun 2018, standar pelayan penumpang menurut Peraturan Menteri Perhubungan Nomor 39 Tahun 2015, dan mempunyai fasilitas tambahan untuk Seaplane Bases yang dirancang sesuai dengan standar U.S Departement Of Transportation, Federal Aviation Administration dalam dokumen Advisory Circular (AC) No. 150/5395-1B, dan menggunakan metode benchmarking untuk pelabuhan kapal ferry, wisata, dan Seaplane Bases. Perencanaan pelabuhan wisata ini mempunyai 3 tahapan dalam pembangunannya yaitu tahap I tahun 2020 tahap II tahun 2025 dan tahap III tahun 2040.

\section{DAFTAR PUSTAKA}

[1] U. Januari, "BADAN PUSAT STATISTIK,” no. 68, pp. 1-10, 2019.

[2] R. I. Lukman, "Kajian Kondisi Morfometri dan Beberapa Parameter Stratifikasi Perairan Danau Toba.," J. LIMNOTEK., vol. 4, no. 3, pp. 2010-2011, 2011.

[3] esti yulitriani tisnaningtyas andreas agung widhijanto, "IDENTIFIKASI KAWASAN PERMUKIMAN PENDUKUNG: ANALISIS PROXIMITY PENGEMBANGAN DESTINASI WISATA DANAU TOBA," vol. 4, no. 1, 2018.

[4] H. A. Devy and R. B. Soemanto, "Pengembangan Obyek Dan Daya Tarik Wisata Alam Sebagai Daerah Tujuan Wisata Di Kabupaten Karanganyar (Studi Kasus Obyek Wisata Air Terjun Jumog di Kawasan Wisata Desa Berjo, Kecamatan Ngargoyoso, Kabupaten Karanganyar)," J. Sosiol. DILEMA, vol. 32, no. 1, pp. 34-44, 2017.

[5] P. 61 T. 2009, "PP 61 TAHUN 2009," Society, vol. 3, p. 464, 2009.

[6] P. 3 T. 2018, "PM 3 TAHUN 2018," Isbn, vol. 4, no. 1, pp. 121-138, 2018.

[7] Menteri Perhubungan, "PM_39_Tahun_2015.pdf." 2015.

[8] U.S. Department of Transportation. Federal Aviation Administration and Federal Aviation Administration, "Advisory Circular Advisory Circular," Aviation, vol. 1, no. AC 25.1529-1A, pp. 1-2, 2012.

[9] HARYADJI, "Markas besar angkatan udara staf ahli kajian penggunaan pesawat amfibi cl-415 untuk mendukung tugas tni dalam rangka omp dan omsp," vol. 29, no. 2, pp. 1-19, 2012.

[10] R. R. R. Rinaldi and H. A. Kurniawati, "Desain Kapal Amfibi Water School Bus sebagai Sarana Transportasi Pelajar untuk Rute Pelayaran Kepulauan Seribu - Jakarta Utara,” J. Tek. ITS, vol. 7, no. 1, pp. 1-5, 2018, doi: 10.12962/j23373539.v7i1.29352.

[11] M. R. Yuwanda, Y. Muliati, and S. Nurdin, "Pengembangan Pelabuhan Batu Panjang Kabupaten Bengkalis Provinsi Riau," vol. 2, no. 4, 2016.

[12] JUKNIS, “JUKNIS,” J. Chem. Inf. Model., vol. 53, no. 9, pp. 1689-1699, 2013.

[13] B. Triatmojo, "PERENCANAAN PELABUHAN, vol. 7, no. 2, pp. 1-16, 2557.

copyright is published under Lisensi Creative Commons Atribusi 4.0 Internasional. 